\title{
Renovation and improvement of the historical part of the city park
}

\author{
Olga Polyakova ${ }^{1, *}$ \\ ${ }^{1}$ Togliatti State University, 445020, Belorusskaya Street, 14, Tolyatti, Russia
}

\begin{abstract}
The purpose of renovating the urban territory is to develop a cultural environment, create a promising cognitive landscape object attractive to the population, children and youth, as well as to promote the activation of domestic and inbound tourism. Given that one of the main areas of scientific, technical and production activity in the Samara region of Russia is: development, design, production, operation of aerospace equipment, renovation of the allocated territory is focused on displaying the space. Architectural, design and landscape solutions aimed at creating a set of thematic historical and recreational functional areas on the territory of Cosmonauts Boulevard of the Avtozavodsky District of the city of Togliatti, as well as the Information Center pavilion, including new computer presentation tools, architectural models, were developed. The project is in line with the strategies for socio-economic development of the city and the region until 2030, and is supported by the administrations and public funds of the region.
\end{abstract}

\section{Introduction}

The city of Tolyatti, the Samara region of Russia, is located at the bend of the Volga River Samarskaya Luka, on the left bank of the Kuibyshev reservoir - the Zhigulevsky Sea, opposite the Zhigulevsky Mountains. The Samarskaya Luka National Park and the Zhigulevsky Biosphere Nature Reservation are located in the mountains of the coast.

Tolyatti is the Territory of Advancing Socio-Economic Development of the Russian Federation - an economic zone with preferential tax conditions and other privileges defined for attracting investments, accelerating economic development, improving the life of the population, when implementing national projects whose implementation is set for 2019$2024[1,2]$. Relevant for the city is development of the cultural environment, improving cognitive attractiveness of the region, contributing to the education of children and youth, revitalization of domestic tourism $[3,4]$.

One of the main areas of scientific, technical and industrial activity in the Samara region is development, production, maintenance of aerospace technology. Accordingly, the display of the direction of space in the cultural environment of the region is in demand. The implementation of the regional project "Samara - the space capital of Russia", with highlighted municipal fragments, including the project section: "Station - Togliatti", the

\footnotetext{
* Corresponding author: om design@mail.ru
} 
object of which is Cosmonauts Boulevard at the Avtozavodsky district of Togliatti [5, 6], is oriented towards solving this problem, development of international scientific and technical cooperation, and innovative development of the national economics.

Examples of the implementation of the objects of the developed regional project: a commemorative stela "To the Conquerors of Space" and the avenue "Stars of Space" are shown in Fig. 1 and 2.

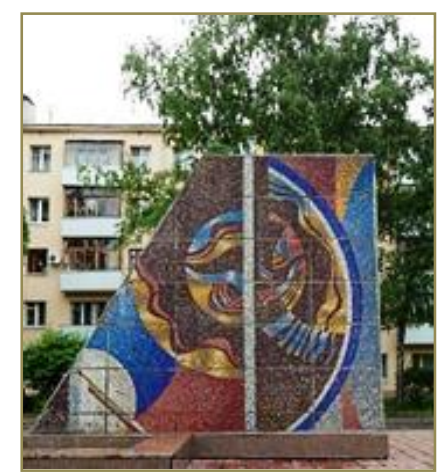

Fig. 1. Commemorative stele "Conquerors of Space" in the square of the First Cosmonauts, Kirovsky district, the city of Samara.
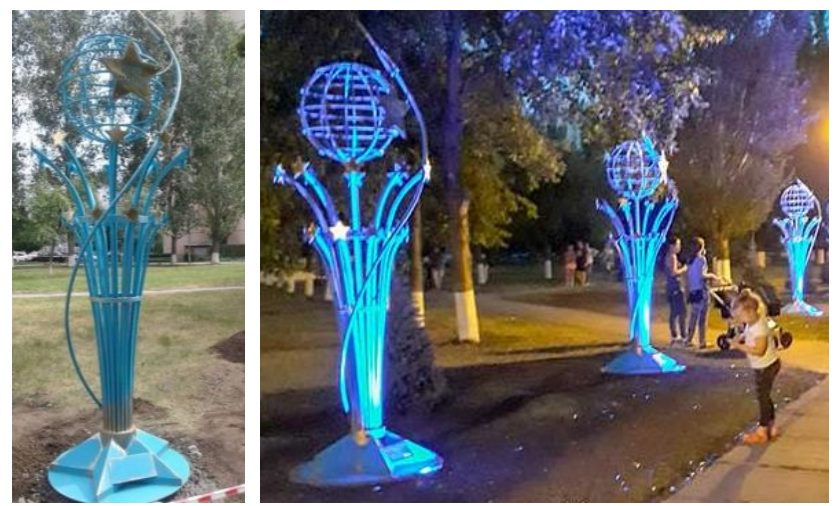

Fig. 2. Compositions "Cosmos Stars", with registered commemorative panels, on the boulevard of Cosmonauts, Avtozavodsky district of the city of Togliatti.

The prospective development of the regional section of the "Station-Tolyatti" project is ensured by architectural and design development, the formation of a set of thematic and recreational functional zones, the Information Center pavilion on the territory of Cosmonauts Boulevard, including computer presentation tools for relevant historical events, architectural models of individual objects.

In order to develop the economy, to improve the life of the population, and to increase the investment attractiveness, in accordance with the development strategies of the city and the region, the implementation of activities focused on the implementation of the regional project and its municipal components, including the renovation and improvement of the boulevard territory, is necessary.

At the same time, assistance is provided in stabilizing the personnel potential, and engaging youth contingents, professionally trained, and promising specialists in activities in the city district and region [7]. Implementation of the project increases the development, efficiency in the economy of the region of the tourism cluster through the development of domestic and inbound cognitive tourism [8]. 
Solving the tasks using the technologies of architectural and design development of the cultural environment, increasing the cognitive attractiveness of the urban territory in the space direction are relevant, innovative and effective. Direct analogues of architectural, design solutions are unknown.

\section{Architectural and design development of objects of the Cosmonauts Boulevard}

The design strategy for the complex of boulevard facilities is focused on solving a number of interrelated tasks: improvement of the territory of the Avtozavodsky district of Tolyatti; the formation of a base for educational excursions for children and youth, the development of domestic and inbound tourism, the integration processes of the Samara-Togliatti agglomeration; actualization of the interaction of university students in Togliatti and Samara [9]. The priority of renovating the territory of Cosmonauts Boulevard was determined both by the presence of the regional project "Samara - the space capital of Russia", with the municipal fragment "Station - Togliatti", and the expansion of space activities, increasing interest in this area of development of countries, regions, and active populations.

The implementation of system technologies of architectural and design development of the innovation complex is aimed both at the formation of iconic objects, and at increasing attractiveness, improvement of public areas, landscape design:

gardening, modernization of the road-path network; creation of a set of specialized functional zones, including platforms for various purposes for ceremonies, film screenings, quiet relaxation, activities with children in which guests and residents of the city are interested $[10,11]$.

The essential meaning for achieving the goal, for solving problems that are relevant for the city and the region is the implementation of the general system principles of architectural and design development, the formation of attractive and informationally significant open-air public spaces $[12,13]$.

When developing a comprehensive project for the renovation of the territory, the results of the accomplished work on the improvement of the objects of the city district, as well as on the development of the cultural environment of the regional agglomeration using information technologies, were taken into account $[14,15]$.

General plan of the boulevard is formed with allocation of functional zones for different purposes:

- entrance zone / arch on Cosmonauts Boulevard (1);

- first in space / first satellite, first astronaut (2);

- space stations on Earth orbit (3);

- moon rovers / robots at the Earth satellite (4);

- teusable space system "Buran" (5);

- the "Cosmos Stars" commemorative alley (6);

- boulevard Information Center (7);

- educational children's playground (8);

- outdoor cinema and festivals pavilion (9);

- square "Leisure" / quiet rest (10).

The territory of the boulevard is formed in a regular style, which focuses the attention of tourist groups, local people, participants in relevant events on the information objects of functional zones.

The first object of the psychological orientation of visitors is a large-format arch with volumetric color images of the starry sky, the sun and planets of the solar system, located in the entrance zone. Zones history of astronautics contain large-format steles with volumetric 
color images corresponding to the theme of each functional zone. Images with space objects are freely available on the Internet.

The modular pavilion of the "Boulevard Information Center" zone is designed for thematic excursions, group events; it contains computer presentation tools, including content generated according to the profile of the object, as well as the presentation of tourist routes of the city and region.

\subsection{Functional zone 1. Entrance zone / arch at the Cosmonauts Boulevard}

The structural diagram of the main object of the functional area - the commemorative arch is shown in Fig. 3.

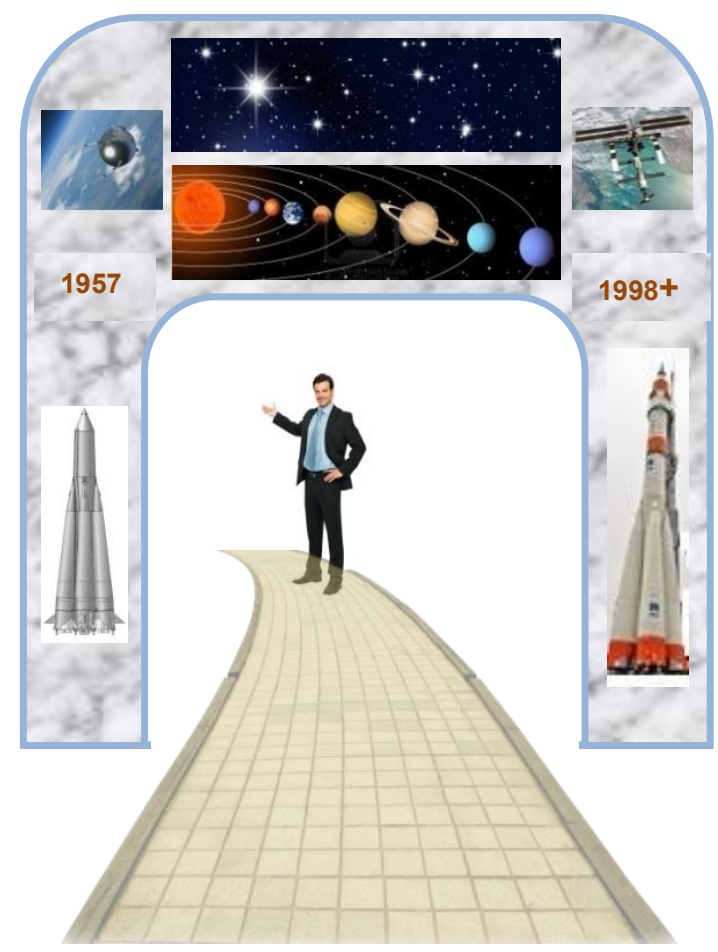

Fig. 3. Memorial arch of the entrance zone, landscape design component: path to the objects of the boulevard territory.

The arch presents introductory thematic images (implementation in the form of volumetric color compositions):

- the upper part, the central module of the entrance arch - the starry sky, the sun and the planets of the Solar system;

- the left pillar of the arch is the R-7 "Sputnik" and "Sputnik-1" launch vehicles, the first spacewalk, 1957;

- the right pillar of the arch is the "Soyuz" launch vehicle, the International Space Station (ISS), operation from the end of 1998 to the present.

Detailing of top thematic images is in Fig. 4, including a text information module Planets of the Solar System: Mercury, Venus, Earth, Mars, Jupiter, Saturn, Uranus and Neptune (in order of distance from the Sun). 

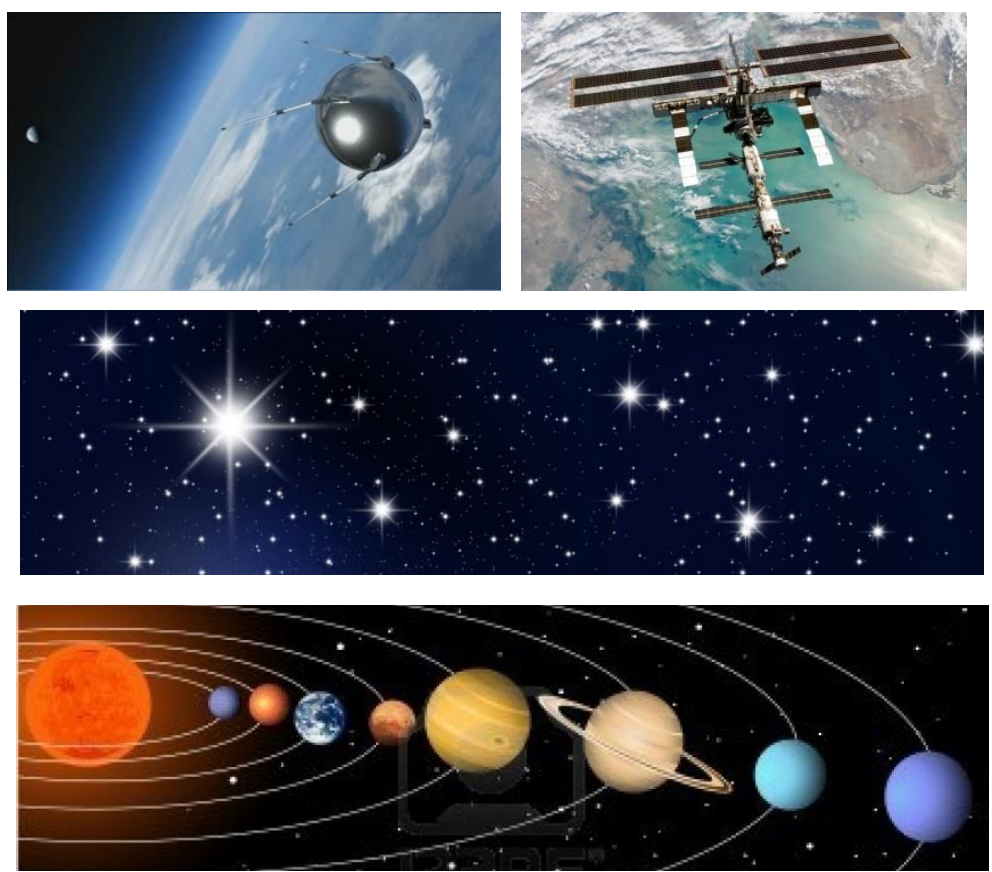

Fig. 4. Images of volumetric color compositions the upper part of the arch of the entrance arch of the Cosmonauts Boulevard.

\subsection{Functional zone 2. First in space / first satellite, first astronaut}

The structural diagram of the main object No. 1 of the functional zone - the commemorative stele "The first satellite in space" is shown in Fig. 5.

The stele contains thematic images and engraved text panels in Russian and in English (left and right or top and bottom):

- the upper part, the central module of the stele with integrated text panels - "Sputnik1 " against the background of a panorama of the earth's surface;

- the left part of the stele is the P-7 family "Sputnik" launch vehicle, which provided the first ever spacewalk of the object;

- the central part of the stele - the launch of the R-7 launch vehicle with a satellite on October 4, 1957 from the "Baikonur" cosmodrome, the Republic of Kazakhstan (on the territory of the "Turatam" polygon of the USSR Ministry of Defense);

- the right side of the stele - Sputnik-1 exit into outer space from the top of the launch vehicle.

After a successful launch and flight of an object around the Earth, the word "satellite" immediately entered the languages of all the peoples of the world.

The structural diagram of the main object No. 2 of the functional zone - the commemorative stele "The First Cosmonaut of the Earth" is shown in Fig. 6.

The stele contains thematic images and engraved text panels in Russian and in English:

- the upper part, the central module of the stele with text panels - the first pilotcosmonaut of the USSR Yuri Alekseevich Gagarin, in the spaceman's spacesuit; 


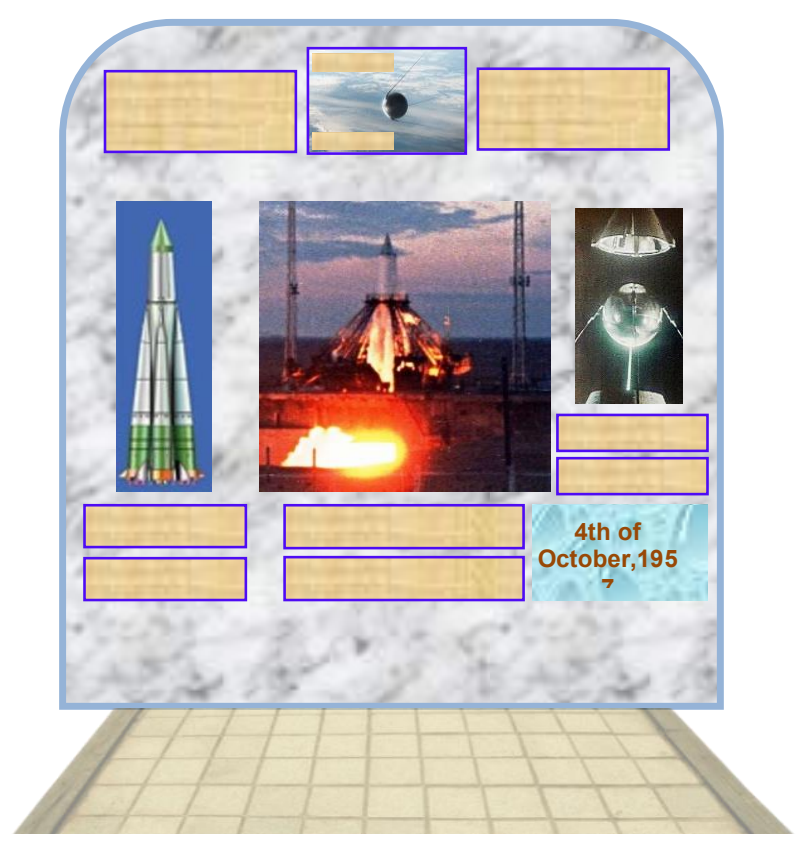

Fig. 5. Thematic stele "The first satellite of the planet Earth" and the landscape design component of a functional area.

- the left side of the stele is the R-7 family "Vostok" launch vehicle, which provided the first space flight in history; the development and production of R-7 two-stage intercontinental ballistic missiles was carried out by the "Progress" Rocket and Space Center, the city of Kuibyshev, currently the city of Samara;

- the central and right parts of the stele are the "Vostok-1" spaceship with the first astronaut on board, in orbit around the earth, 12th of April, 1961.

\subsection{Functional zones: $3,4,5$}

The names of the zones with explanations are given above. Zones are formed using thematic stelas with volumetric color images corresponding to the themes of each functional area, with engraved text panels in Russian and English, using landscape design tools, in the style shown in Fig. 5 and 6. 


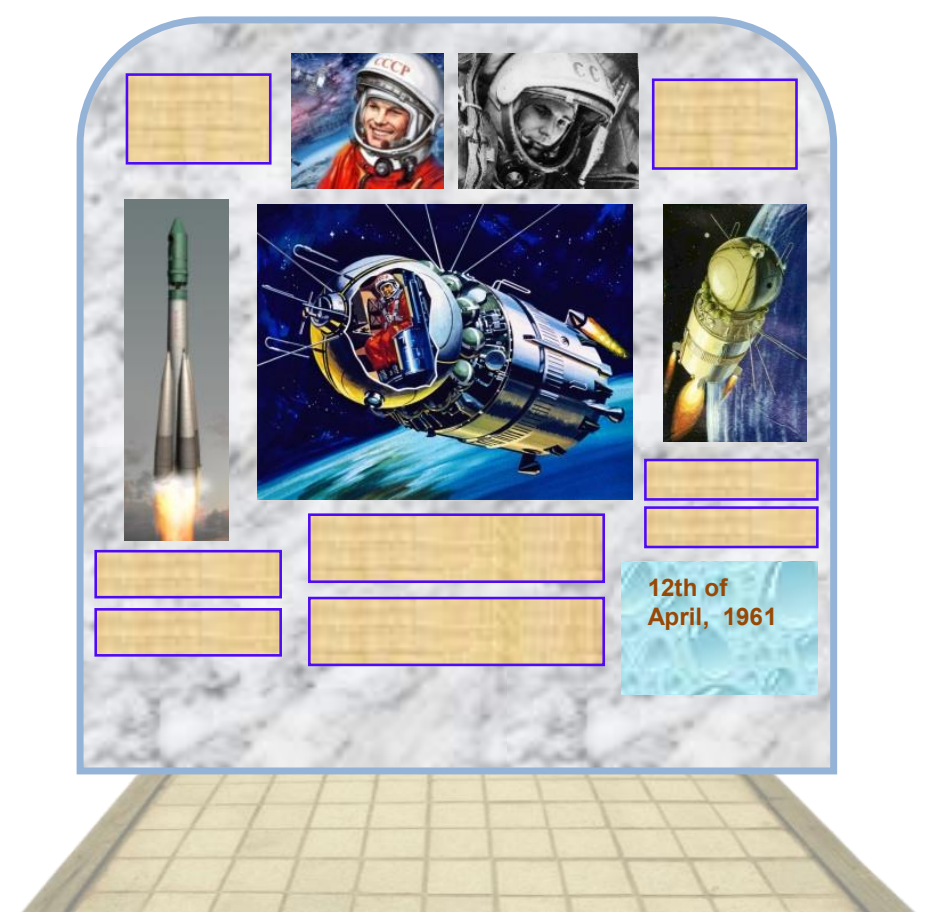

Fig. 6. Thematic stele "The First Cosmonaut of the Earth" and landscape design component of a functional area.

\subsection{Functional zone 6. "Cosmos Stars" Alley}

Compositions of commemorative themed objects, created in Tolyatti in 2018, installed on Cosmonauts Boulevard, are shown in Fig. 2. Further, it is planned to improve the alley, to continue the formation of "star" compositions dedicated to new achievements in space exploration.

\subsection{Functional zone 7. Boulevard Information Center}

Creation of the information center of the Cosmonauts Boulevard is ensured by the formation of a specialized pavilion, the option - Fig. 7. The phased-developed facility is equipped with computer-based presentation tools, dynamic architectural models on the subject of the regional project "Samara - the space capital of Russia". The history of space exploration began with the use of rockets created in the city of Samara, earlier: Kuybyshev. The launch vehicle that launched Yuri Gagarin into space was made here at the "Progress" Rocket and Space Center.

Currently, Samara has become the capital of world-class spaceports: "Baikonur", Republic of Kazakhstan; "Plesetsk", Arkhangelsk Region of Russia; "Kourou", French Guiana; "Vostochnyy", Amur region of Russia.

"Soyuz" rockets are launched from four cosmodromes. In the city - the "space capital of Russia", rockets, engines, satellites are produced, including for remote sounding of the Earth; personnel are being trained for high-tech enterprises. 


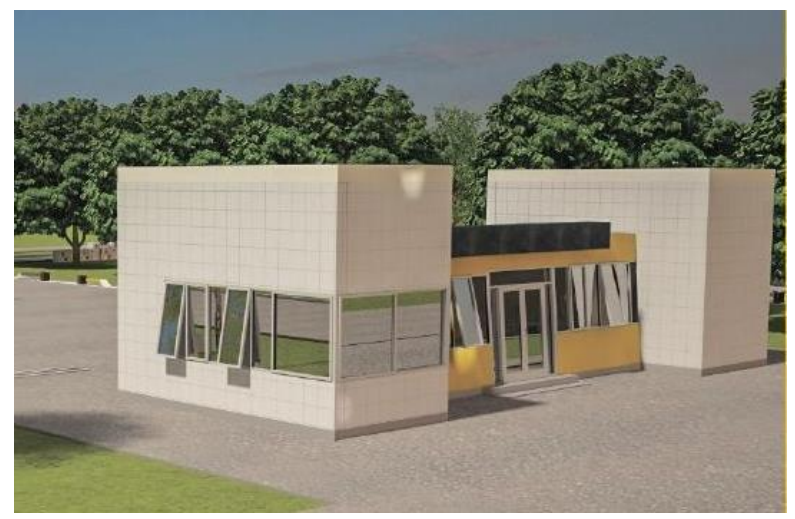

Fig. 7. Appearance of the pavilion of the formed Information Center at the Cosmonauts Boulevard.

\subsection{Functional zone 8. Children playground}

The arrangement of the educational playground is supposed to be carried out using typical components that provide gaming employment and physical development of children, supplemented by modules with a "space orientation", the option - Fig. 8.

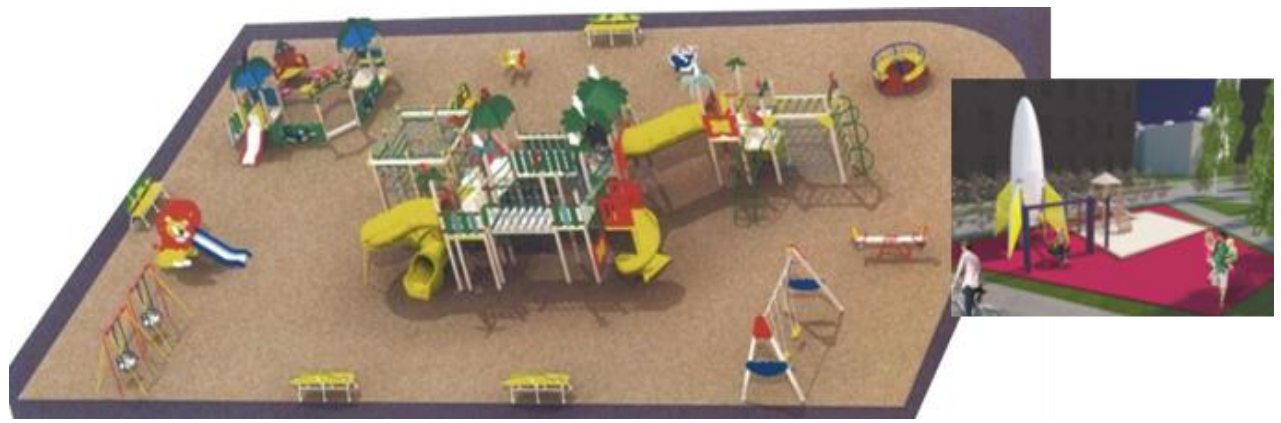

Fig. 8. The appearance of the developed playground at the Cosmonauts Boulevard.

\subsection{Functional zone 9. Outdoor cinema and pavilion of thematic festivals}

An outdoor cinema and a pavilion of thematic festivals are intended for watching specialized films, for arrangement of public events, and to ensure the development of the cultural environment and improvement of the Avtozavodsky district of the city of Tolyatti, the option - Fig. 9, 10.

The cinema is focused on seasonal use; for the autumn-winter season, the building's structures are preserved using special coatings.

The pavilion is the object of the second stage of the boulevard renovation, focused on the future development of the regional project "Samara - the space capital of Russia" in the Samara-Togliatti agglomeration. 


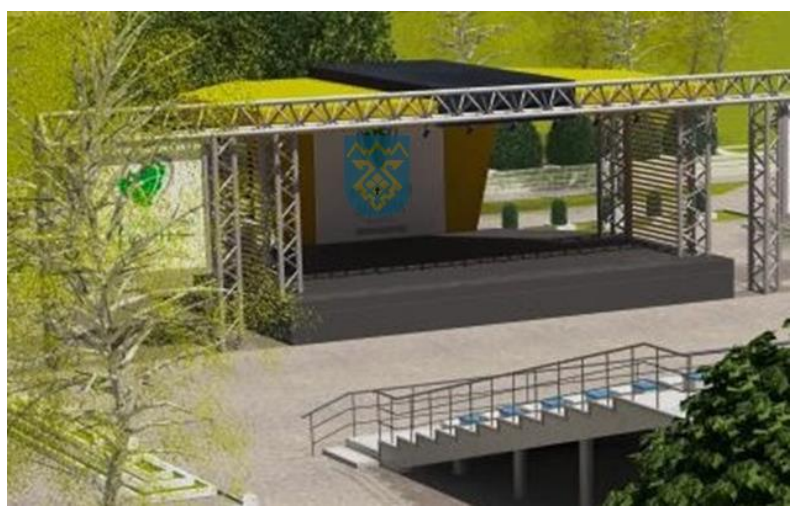

Fig. 9. The appearance of the outdoor cinema formed at the Cosmonauts Boulevard.

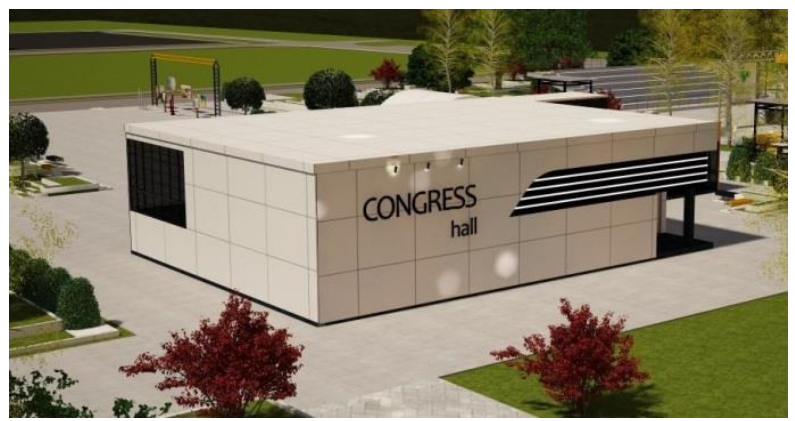

Fig. 10. The appearance of the pavilion of thematic festivals at the Cosmonauts Boulevard.

\subsection{Functional zone 10. Square "Leisure" / Quiet Rest}

The square is being formed, first of all, as an object of improvement of the territory of the Avtozavodsky district of the city of Tolyatti, to improve the life of the population, to increase the attractiveness of the boulevard for visitors of various ages, as a recreation area, including for tourist groups, the assembly is presented in Fig. 11.

In this regard, the object is created as multifunctional, promising also for possible use on the historical and educational profile of the boulevard, including the installation of additional landscape components, including thematic stelas, arches, recreational cultural and leisure fragments. 

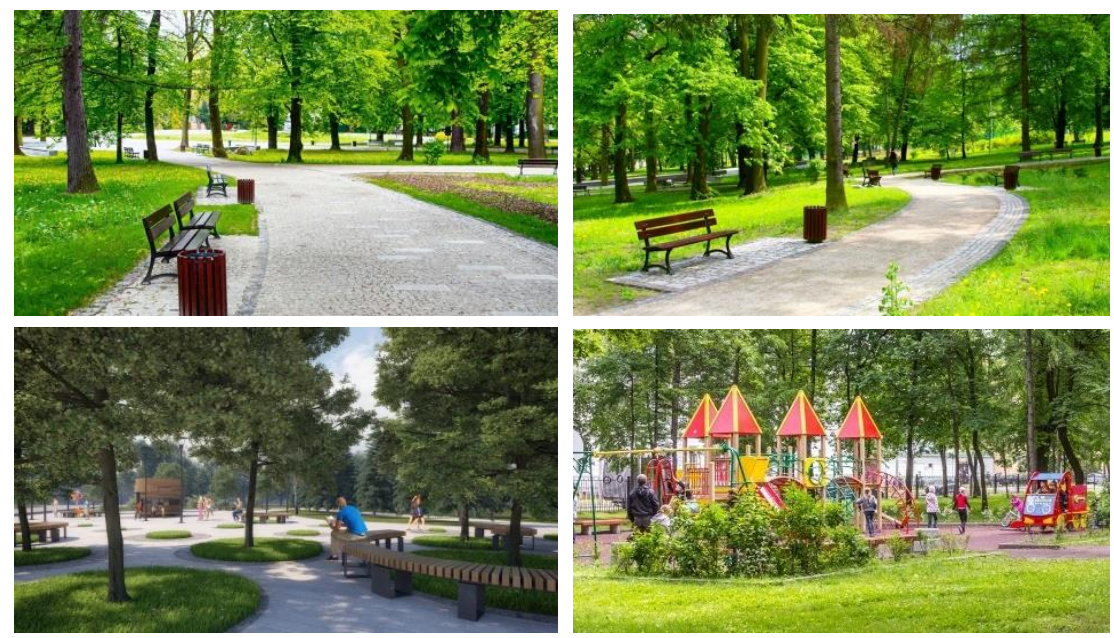

Fig. 11. Fragments of the variant development of the square "Leisure" / quiet rest for the Cosmonauts Boulevard.

\section{Conclusion}

The development of the cultural environment of cities, regions, increasing the cognitive attractiveness of territories, of the objects of renovation and improvement, is important for raising children and youth, for attracting active people to activities at the territories under development, and contributes to the activation of domestic and inbound tourism.

Given that one of the main areas of scientific, technical and industrial activity in the Samara Region of Russian Federation is the development, production, operation of aerospace equipment, the display of the "space" direction in the cultural environment of cities of the region is in demand.

Architectural and design development aimed at solving this task is focused on the presentation of historical events, renovation, and improvement of Cosmonauts Boulevard in the Avtozavodsky District of the city of Togliatti, as a promising object under development of the Samara-Togliatti agglomeration. The strategic renovation of the facility corresponds to the adopted strategies for the socio-economic development of the city and the Samara region until 2030, is supported by the administrations of the city of Togliatti and the region, by the leadership of backbone enterprises and public funds of the region.

The direction of development of the region corresponds to the goals and objectives of the National project of the Russian Federation "Environment comfortable for life".

Within the design, the general design concept of a promising complex under development was implemented, which provides the formation of a set of thematic and recreational functional areas, the "Information Center" pavilion, including computer presentation tools, architectural models, on the territory of Cosmonauts Boulevard. Working design of fragments of the object, the implementation of architectural and design developments are planned to be phased, starting in 2020, in the cooperation of regional coexecutors. 


\section{References}

1. O.B. Ivanov, E.M. Buchwald, STEP: economic theory, analysis, practice, №1, 37-53 (2019) DOI: 10.24411/2071-6435-2019-10067/

2. A.Ya. Zaporozhan, Management Consulting, №5 (125), 18-23, RANEPA, Moscow (2019) DOI 10.22394/1726-1139-2019-5-18-23/ H.Z. Halimbekov, Z.R. Shakhbanova, Bulletin of the Association of Tourism and Service Universities, 9, № 2, 34-39 (2015) DOI: $10.12737 / 11295 /$

3. I.V. Tsvetkova, Vector of Science of Togliatti State University, № 3 (41), 152-157 (2017) DOI: 10.18323/2073-5073-2017-3-152-157/

4. A.P. Krishtofor, University Bulletin, № 4, 62-66, State University of Management, Moscow (2019) DOI: 10/26525/1816-4277-2019-4-62-66/

5. V.V. Glukhov, E.O. Serova, Scientific and Technical Journal of St. Petersburg State Polytechnic University. Economic Sciences, № 4 (246), 76-84 (2016) DOI: 10.58.62/JE 246.7/

6. Yu.V. Vertakova, O.N. Grechanok, A.V. Grechanok, Scientific and Technical Sheets of St. Petersburg State Polytechnic University. Economic Sciences, №. 1 (211), 84-92 (2015) DOI: 10.5862/JE 211.8/

7. G.A. Ptichnikova, O.V. Chernichkina, Vestnik of Samara Technical University, 9, № 2, 53-60 (2019) DOI: 10.17673/Vestnik.2019.02.8/

8. E.M. Shuvalova, S.G. Malysheva, Urban Planning and Architecture, 7, № 2, 85-88, Samara Technical University (2017) DOI: 10.17673/Vestnik.2017.02.13/

9. N.A. Orlova, D.N. Orlov, V.V. Molchanova, Urban Planning and Architecture, 8, № 3 (32), 99-105 (2018) DOI: 10.17673/Vestnik.2018.03.19/

10. E.A. Akhmedova, Innovative Project, 1, № 2 (2), 72-76, Samara State Technical University (2016) DOI: 10.17673/IP.2016.1.02.10/

11. I.V. Kukina, Y.V. Chui, A.A. Gorsha, Urban Planning and Architecture, 9, № 4 (37), 132-139 (2019) DOI: 10.17673/Vestnik.2019.04.19/

12. O.M. Polyakova, E3S Web of Conferences, 135, 03011 (2019),

13. O.M. Polyakova, IOP Conference Series: Materials Science and Engineering, 698, Architecture, design, reconstruction and restoration of architectural heritage, 033012

14. O.M. Polyakova, IOP Conference Series: Materials Science and Engineering, 698, 022009 (2019) 